exercise as an aetiological factor has been reported. ${ }^{4}$

Compartment syndrome of the thigh remains an uncommon finding, but a high index of clinical suspicion should be maintained in the patient with a relevant history and suggestive physical signs. The patient had a painful swollen thigh and passive flexion of the knee caused severe pain in the anterior compartment of the thigh. Compartment pressures can be recorded by the bedside and in this case confirmed a markedly increased pressure in the anterior compartment, with a moderate increase in the posterior compartment. Prompt fasciotomy of both compartments was performed.

Weight training and body building have become increasingly popular forms of sport and recreation. Well supervised training, with particular emphasis on the importance of gentle stretching and warming up, is vital to reduce the multitude of soft tissue injuries that result, and without doubt would have prevented the scenario that we encountered in this case.

1 Mubarak SJ, Hargens SR, Owen CA, Garetto LP, Akeson WH. The wick catheter technique for measurement of WH. The wick catheter technique for measurement of intramuscular pressure: a new research

2 Schwartz JT, Brumback RJ, Lakatos R, Poka A, Bathon GH Burgess AR. Acute compartment syndrome of the thigh. A spectrum of injury. F Bone foint Surg Am 1989;71A:392 400 .

3 Klasson SC, Vander Schilden JL. Acute anterior compartment syndrome of the thigh complicating quadriceps haematoma. Two case reports and review of the literature. Orthop Rev 1990;19:421-7

4 Kahan JSG, McClellan SRT, Burton DS. Acute bilateral compartment syndrome of the thigh induced by exercise. $f$ Bone foint Surg Am 1994;76A:1068-71.

5 Reneman RS. The anterior and lateral compartment

syndrome of the leg due to intensive use of muscles. Clin Orthop 1975;113:69-80.

\title{
Distant entry pneumothorax in a competitive fencer
}

\author{
Peter A Harmer, James Moriarity, Mark Walsh, Michael Bean, Joni Cramer
}

\section{Department of \\ Exercise Science, Willamette University, Salem, Oregon, USA \\ P A Harmer}

University of Notre Dame, South Bend, Indiana, USA

$\mathrm{J}$ Moriarity

St Joseph's Medical Center, South Bend, Indiana, USA

$M$ Walsh

Department of Athletics, University of Notre Dame, South

Bend, Indiana, USA M Bean

California University of Pennsylvania, California, Pennsylvania, USA J Cramer

Correspondence to: Dr Peter A Harmer, Department of Exercise Science-Sports Medicine, Willamette University, Salem, OR 97301, USA.

Accepted for publication 16 January 1996

\begin{abstract}
An elite level fencer sustained a penetrating wound to the upper arm after his opponent's blade broke. Standard care for a deep puncture wound was given but it was some time before the athlete presented symptoms of a pneumothorax, which was confirmed by radiograph. Although resolution of this case was unremarkable, the possibility of penetrating thoracic injury, even when the point of entry is well outside the thorax and the athlete is not immediately symptomatic, should be born in mind by medical personnel working with fencers.

(Br F Sports Med 1996;30:265-266)
\end{abstract}

Key terms: fencing; penetrating wound; pneumothorax

Pneumothorax is an uncommon injury in noncontact sports. Fencing, although defined as a non-contact sport, involves fast and powerful blade contact with various parts of an opponent's body (principally the torso). Despite its heritage of lethal intent, there is little evidence to indicate that fencing is a hazardous activity. ${ }^{1-3}$ However, there is an inherent risk of serious injury especially when blades break, because of the probability of lacerations or penetrating wounds from rigid remnants. The thoracic wall (right side for right handed fencers; left for left handed fencers) is particularly vulnerable. It is left exposed as fencers align themselves in the typical en guarde position, that is, along the frontal plane with the fencing arm abducted, exposing the axilla and lateral thoracic wall to the opponent's blade. Incidents of penetrating wounds are well known to competitive fencers but are not well documented in published reports in general medical or sports medicine journals. The present case is an example of a complex penetrating wound involving a pneumothorax from a broken blade.

\section{Case report}

A right handed elite level American fencer was competing in an epee tournament. During a thrusting manoeuvre his opponent's blade struck the guard on the victim's weapon and was fractured. The remnant of the blade (still attached to the opponent's handle) continued its forward momentum scraping the volar surface of the victim's right arm penetrating it at a point $12 \mathrm{~cm}$ distal to the anterior axillary line (fig 1). The fencer experienced an unusual discomfort in his back but remained unaware of his injury until a large amount of blood became evident on the upper sleeve of his outer garment. The match was discontinued and the wound was inspected and a compression bandage applied. Chest pain was noted to be present, specifically when the fencer was lying flat. Vital signs were normal and chest auscultation revealed equal breath sounds. The fencer was transported to hospital for further evaluation. In the emergency department the fencer continued to experience chest discomfort remarkably similar to his remembered asthma attacks as a child. Breath sounds were noted to be slightly diminished on the right side and a chest radiograph was requested. 


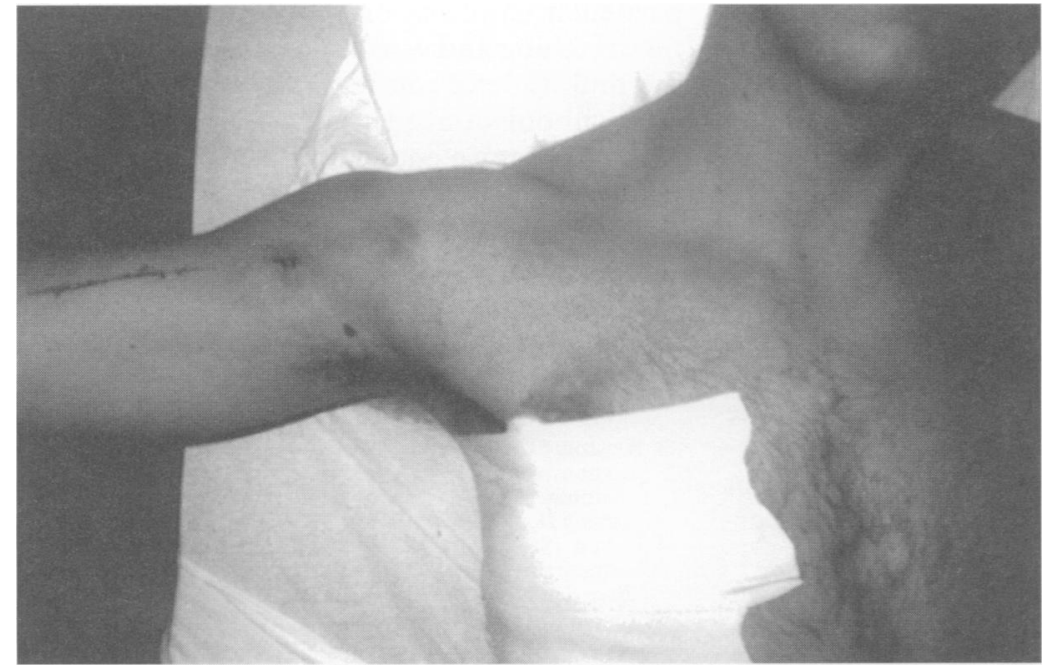

Figure 1 Abrasion line and point of entry (arrow) into arm.

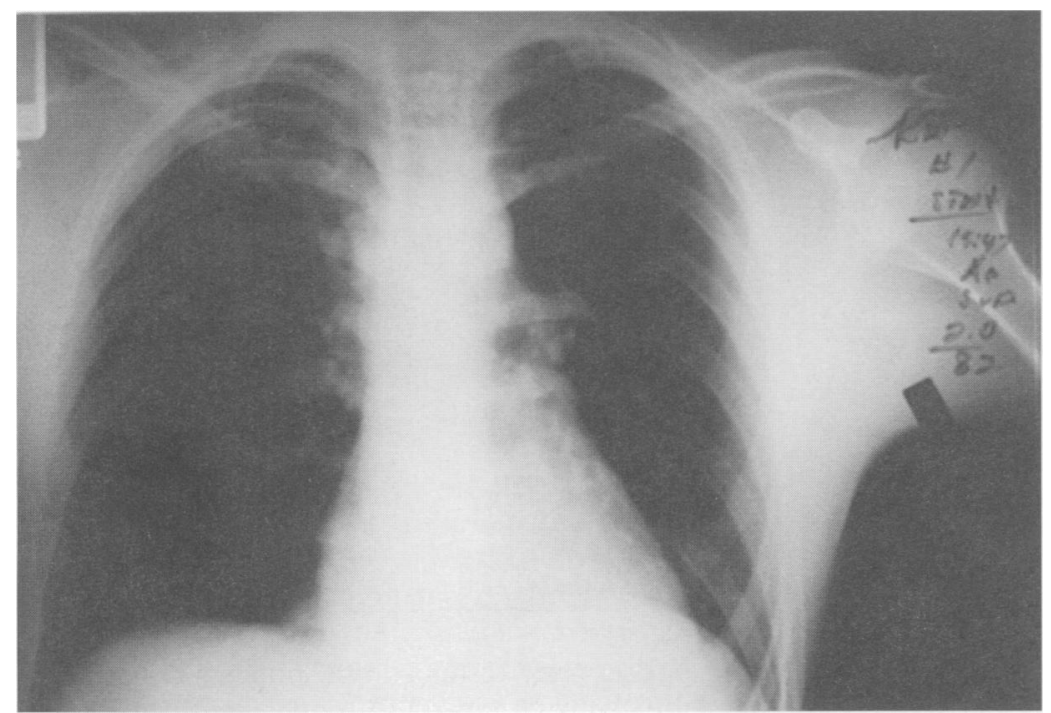

Figure 2 Radiograph of pneumothorax following distant entry wound injury.

While in the radiology department the fencer became acutely diaphoretic, dyspnoeic, and hypotensive. The chest radiograph revealed a $50 \%$ tension pneumothorax (fig 2 ). Subcutaneous emphysema was present. A chest tube was inserted in the fifth intercostal space with prompt resolution of symptoms and reexpansion of the lung.

The fencer remained as an inpatient for the next five days. His stay was uncomplicated except for an unexplained weight loss of $6.8 \mathrm{~kg}$ (15 pounds). A two year follow up revealed full and complete recovery.

\section{Discussion}

There have been at least three fatalities in elite level fencing competition from direct penetration of the thorax by broken blades. ${ }^{45}$ Nonfatal episodes of varying severity have also been noted. ${ }^{3}$ The fencing arm of epee fencers is also susceptible to puncture wounds because it is a valid target in this weapon. ${ }^{1}$ Finally, broken blades being deflected into an opponent's head or neck after catching on the sleeve during an attack have resulted in several fatalities. $^{5}$

Given the nature of the sport and a history of fatal (though infrequent) incidents, participant safety has been a major concern of fencing authorities. Current regulations require that protective clothing be made of kevlar or ballistic nylon with a minimum rating of 800 Newtons. Recognising the particular vulnerability of the exposed axilla, rules require the wearing of an $800 \mathrm{~N}$ plastron, an extra garment worn under the jacket and designed to cover the upper quadrant of the torso on the fencing arm side as well as the proximal half of the fencing arm. Blades must be made of fracture resistant maraging steel which breaks with a flat rather than a jagged edge, decreasing the likelihood of penetration of the protective clothing. Unfortunately, most equipment regulations are compulsory only for international competition. The use of less durable protective clothing and poorer quality blades by the majority of fencers places them at risk of penetrating wounds. The recent death of an epee fencer in France highlights the need for medical personnel working with fencers to be aware of the aetiology, variations, and complications presented by these injuries.

The pneumothorax in the present case is thought to have occurred in the following manner: the fractured epee penetrated the fencer's protective garment, passed through the skin of the arm, and tunnelled in the deltopectoral space anterior to the axillary triangle before entering the chest cavity in the second or third intercostal space. There were no peripheral neurovascular deficits in the arm or hand to indicate injury to the axillary structures.

Tension pneumothorax can occur even when trauma is well removed from the thoracic cavity. ${ }^{67}$ For unknown reasons, penetration of the thorax in this case was not demonstrated until well after the patient's first physical examination. This incident is also interesting in that it circumvented the protection provided by the plastron by entering the arm below the distal end of the plastron and travelling through the arm to the thoracic wall. The same mechanism was probably partially responsible for at least one fatality. ${ }^{4}$

Although the clinical features of this case were unremarkable, it is noteworthy as a sports specific example of damage removed from the site of penetration and for the significant time lag between infliction of the wound and subsequent demonstration of the pneumothorax.

1 Baker CL. Comments on Olympic sports medicine: the Modern Pentathlon. Am 7 Sports Med 1983;11:42-5.

2 Roi GS, Fasci A. Indagine sulle richieste di intervento del medico durante le gare di scherma (Survey of requests for medical assistance during fencing matches). Int $\mathcal{f}$ Sports Trauma 1988;10:55-62.

3 Weightman D, Browne RC. Injuries in eleven selected sports. Br $\mathcal{F}$ Sports Med 1975;9:136-41.

4 Crawfurd R. Rapport sur l'accident mortel d'Howard Travis, le 25 Avril 1990, a t'Harde, Pays Bas (Report of the lethal accident of Howard Travis, April 251990 , in t'Harde, The Netherlands). Unpublished report. Fédération Internationale d' Escrime, 1991.

5 Parfitt R. The fencer at risk. In: Armstrong JR, Tucker WE, eds. Injury in sport . London: Staples, 1964:173-90.

6 Lee HC, Dewan N, Crosby L. Subcutaneous emphysema, pneumomediastinum, and potentially life threatening pneumomediastinum, and potentially life
tension pneumothorax. Chest. 1992;5:1265-7.

$7 \mathrm{McNeil}$ P, Gervin DF, Guisto DF. Distance injury pneumothorax. Am f Emerg Med 1989;7:122-3. 